\title{
Analysis and Research on the Stress of All-lightweight Aggregate Concrete Shear Wall with Different Reinforcement Forms
}

\author{
Yanmin Yang ${ }^{1 *}$, Xiaoyu Wang ${ }^{1}$, Runtao Zhang ${ }^{1}$ \\ ${ }^{1}$ School of Civil Engineering, Jilin Jianzhu University, Changchun, P.R. China.
}

Key words: All-lightweight aggregate concrete; Shear wall; Reinforcement form; Seismic performance

Abstract: In order to study the stress and seismic performance of all- lightweight aggregate concrete shear wall under different reinforcement forms, two shear walls were tested under low reversed cyclic loading. The influence of different reinforcement forms on the mechanical properties and seismic performance of the shear wall was compared, which provided a theoretical basis for the practical application of the all- lightweight aggregate concrete shear wall.The test results show that the structure of the fully reinforced concrete shear wall with diagonal brace,compared with ordinary reinforced shear wall,has better mechanical performance and has obviously improved in seismic performance.

\section{Introduction}

As one kind of lightweight aggregate concrete, the structural self-weight of all- lightweight aggregate concrete is far less than ordinary concrete with same bearing capacity. The research on all-lightweight aggregate concrete shear wall in our country is little,and there is no uniform provisions on the current codes and standards.In this experiment, the mechanical characteristics and seismic performance of the all-lightweight aggregate concrete shear wall were studied under different reinforcement forms ${ }^{[1]}$, which can provide a theoretical basis for the seismic design of the all-lightweight aggregate concrete shear wall.

\section{Specimen design and the arrangement of strain gauges}

The experimental study was carried out on two all-lightweight aggregate concrete shear wall specimens. Specimen size and the arrangement of strain gages on reinforcing steel bar are shown in Figure 1,the parameters of steel bar are presented in table 1. Mixture ratio of LC35 are used for the two specimens shown in table 2. 


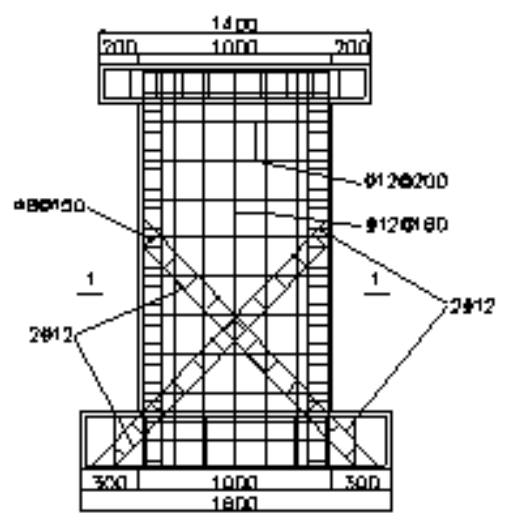

ALACW-1

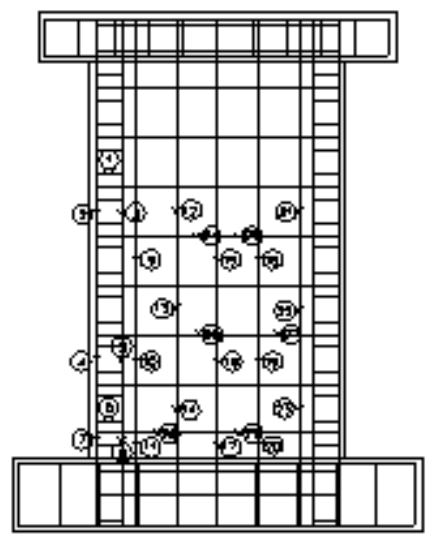

ALACW-1 and ALACW-2 strain gages' placement on steel bar

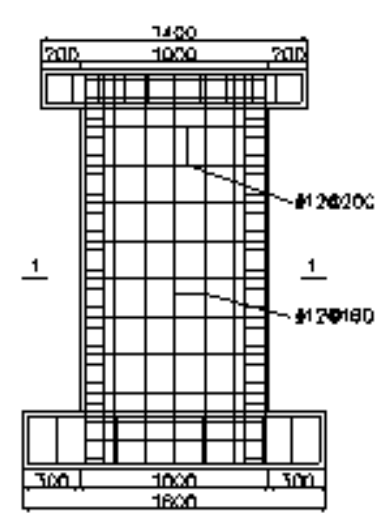

ALACW-2

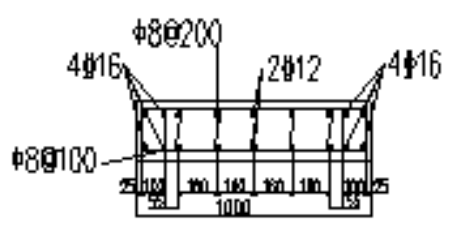

1-1 profile chart

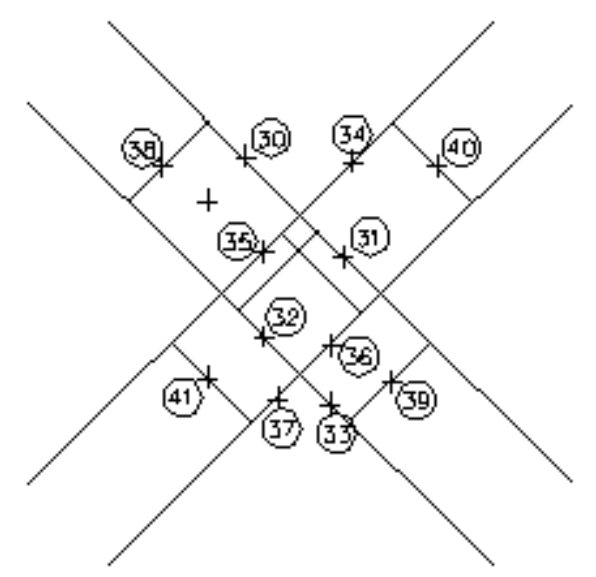

ALACW-1 strain gages' placement at the crossing of sidelong steel bar

Figure 1. Specimen size and the arrangement of strain gages on reinforcing steel bar

Table 1. Parameters of steel bar

\begin{tabular}{c|c|c|c|c|c|c|c}
\hline \multirow{2}{*}{ Specimen } & \multirow{2}{*}{$\begin{array}{c}\text { Height } \times \text { Width } \\
\times \text { Thickness } / \mathrm{mm}\end{array}$} & \multicolumn{2}{|c|}{$\begin{array}{c}\text { Transversely } \\
\text { distributed steel } \\
\text { bar }\end{array}$} & $\begin{array}{c}\text { Longitudinally } \\
\text { distributed steel } \\
\text { bar }\end{array}$ & \multicolumn{2}{c}{ Sidelong steel bar } \\
\cline { 3 - 8 } & \multirow{2}{*}{$1600 \times 1000 \times 160$} & $\begin{array}{c}\text { Spacing } \\
/ \mathrm{mm}\end{array}$ & $\begin{array}{c}\text { Steel } \\
\text { ratio/\% }\end{array}$ & $\begin{array}{c}\text { Spacing } \\
/ \mathrm{mm}\end{array}$ & $\begin{array}{c}\text { Steel } \\
\text { ratio/\% }\end{array}$ & $\begin{array}{c}\text { Spacing } \\
/ \mathrm{mm}\end{array}$ & $\begin{array}{c}\text { Steel } \\
\text { ratio/\% }\end{array}$ \\
\cline { 1 - 7 } ALACW-1 & 200 & 0.707 & 160 & 0.706 & 100 & 1.41 \\
\cline { 1 - 7 } ALACW-2 & 200 & 0.707 & 160 & 0.706 & - & - \\
\hline
\end{tabular}

Table 2. Mixture ratio of LC35

\begin{tabular}{c|c|c|c|c|c|c}
\hline $\begin{array}{c}\text { Strength } \\
\text { grade }\end{array}$ & Cement & Ceramsite & $\begin{array}{c}\text { Ceramic } \\
\text { sand }\end{array}$ & Fly ash & $\begin{array}{c}\text { Water } \\
\text { reducing } \\
\text { agent }\end{array}$ & Water \\
\hline LC35 & 1 & 1.1 & 0.6 & 0.1 & $0.5 \%$ & 0.4 \\
\hline
\end{tabular}

\section{Instrumentation and testing}

In the experiment ,the horizontal load is provided by 500-T capacity MTS electro-hydraulic servo actuator;the vertical load is provided by electro-hydraulic servo loading system of Hangzhou 
POPWIL(100T). In order to ensure the one - to - one correspondence between the collected load and strain,the data is collected by the British IMP data acquisition instrument.Test equipments are presented in Figure 2.

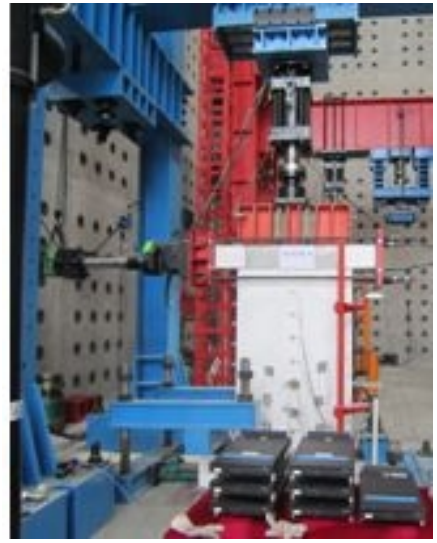

Figure 2. Loading device

Displacement loading system is used to control the loading system in the test, $2 \mathrm{~mm}$ is performed as the displacement increment of the low cycle reciprocating load test until the specimen destroyed.

\section{Hysteresis curve}

The load - displacement hysteretic curves of 2 all-lightweight aggregate concrete shear wall specimens are shown in Figure 3.According to the load- displacement curve,the skeleton curve is drawn as shown in Figure 4.

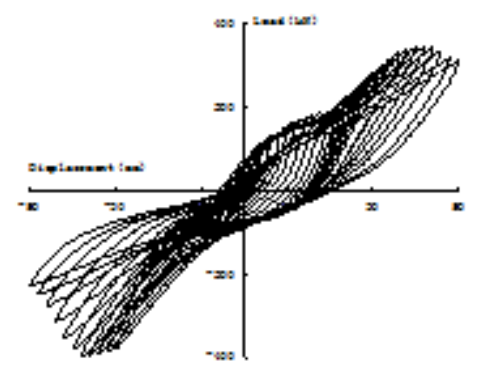

ALACW-1

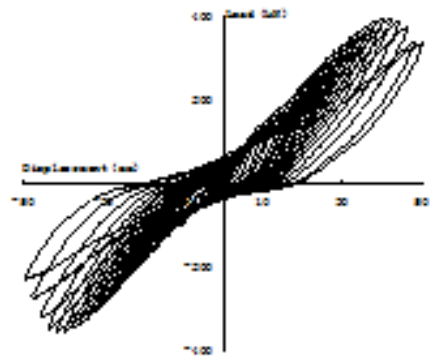

ALACW-2

Figure 3. Hysteresis curve

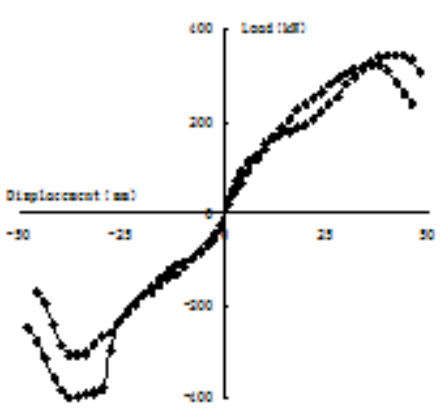

Figure 4. Skeleton curve

From Figure 3 and Figure 4,we can found that the hysteresis curve of ALACW-1,compared with that of ALACW-2,Hysteresis loops are plumper wrapped in a larger area,and the middle part of pinch phenomenon is weaker,and the limit load value is larger. When the load is added to the ultimate load, the down trend of the horizontal load decreases is relatively slower with the increase of the displacement, and the concrete damage is slower, and the appearance of plastic hinge is later. It is showed that the seismic performance of the all-lightweight reinforced concrete shear wall with diagonal brace by ALACW-1 is good, and the energy dissipation capacity is strong; Reasonable arrangement of diagonal steel bar can delay the appearance of plastic hinge of the structure ${ }^{[2]}$; The diagonal steel bar can improve the ultimate horizontal bearing capacity of the structure effectively, slow down the stiffness degradation and enhancement the ductility performance of the structure. 


\section{Strain analysis of steel bar}

The strain of the steel bar of the 2 test pieces is analyzed, and the load - displacement hysteretic curves of the measuring points on distributed steel bar are shown in table 3.The load - displacement hysteretic curves of the measuring points on diagonal steel bar are shown in table 4.

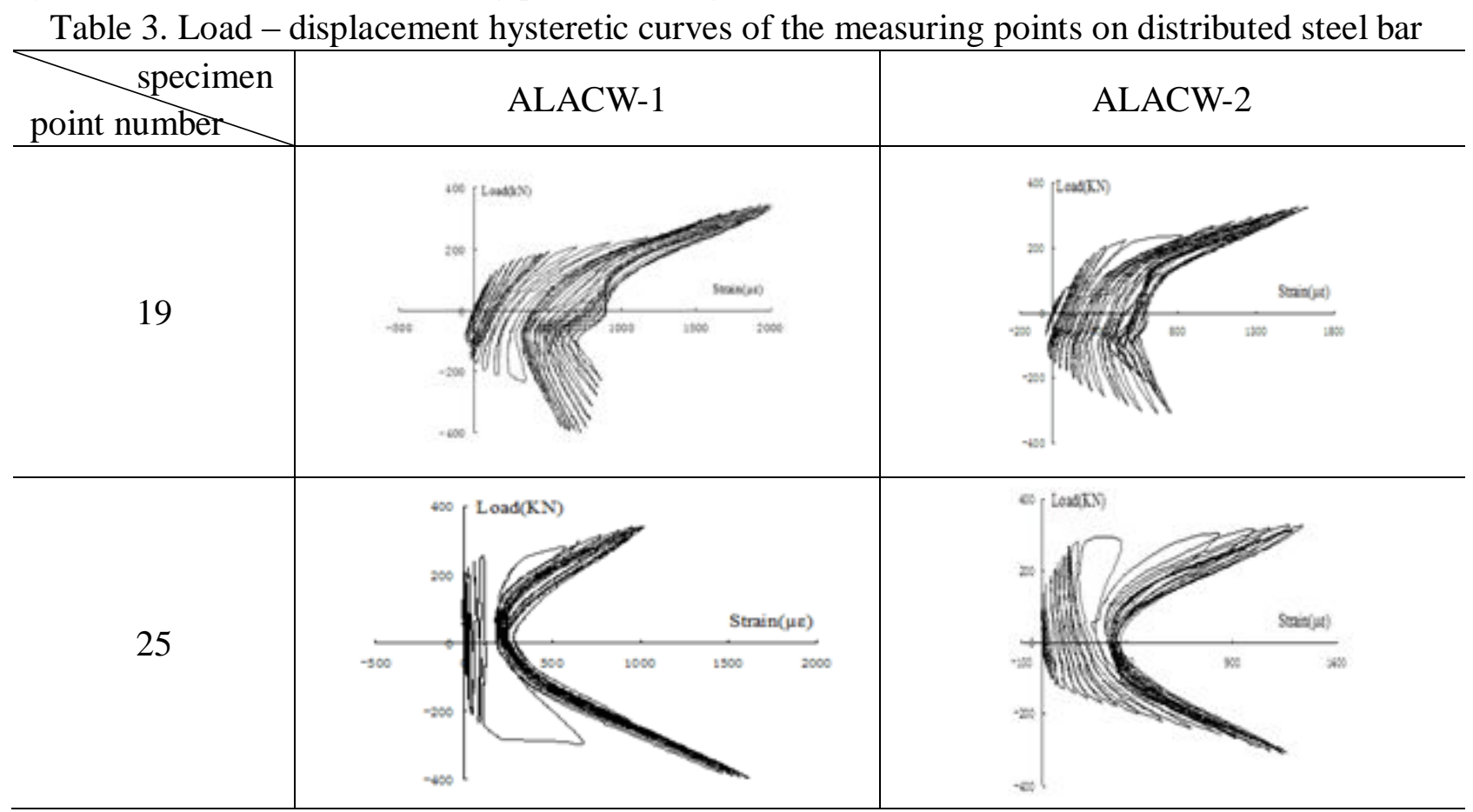

Table 4. Load - displacement hysteretic curves of the measuring points on diagonal steel bar

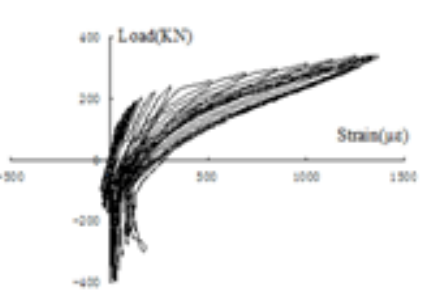

Testing point of 32

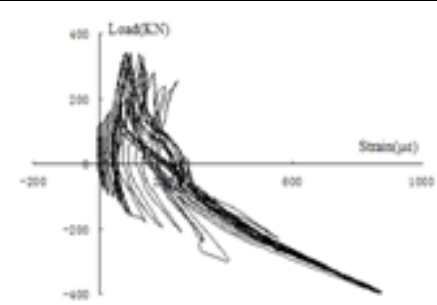

Testing point of 39

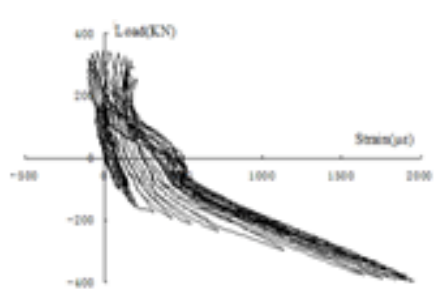

Testing point of 36

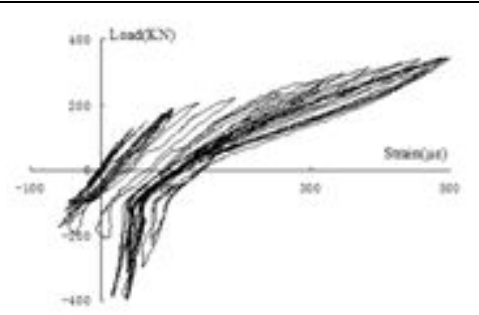

Testing point of 41

From Table 3 and Table 4:

( 1 ) The stress condition of transverse and longitudinal distributed steelbars of ALACW-1 is similar to that of ALACW-2. At the initial stage of the trial, because of the vertical load, the bars are in a state of compression. When the load is not reach the yield load, the load - strain curve of the test points is linear, and the residual strain is small.With the increase of load, the concrete crack, and the residual strain of steel bar has a big change, the load - strain curve of each test point shows a nonlinear variation. 
( 2 ) Contrast the testing points of 19 and 25 with the two test pieces respectively, the strain at the measurement points of the ALACW-1 with the diagonal brace is smaller than that of ALACW-2 with the same position under the same load, and the maximum strain value is greater. It is showed that the strain variation of the distribution reinforcement can be slowed down by the inclined steel bar, and the horizontal ultimate bearing capacity of the structure can be improved.

( 3 ) From the load - strain curve of the testing points 19 and 25, we found that when the reciprocate load is applied, the measuring points are in a state of tension. After steel bar yielding, produce large plastic deformation and the strain increase gradually when exert positive load; When apply reverse load, the strain of the reinforced bar is not synchronized with the forward time due to the large residual strain. With the increase of applied load, the adhesion stress between steel bar and concrete decreases and the slip occurs, which leads to the decrease of the strain value of the bar ${ }^{[3]}$.

( 4 ) When the forward load is carried out, the measurement points 32 and 41 are in tension state and the tensile strain change is relatively large; When apply reverse load, the test points 36 and 39 are in state of compression and the change of the compressive strain is relatively large. It shows that the oblique reinforced can bear part of the shear force, slow down the variation of distribution bar of the shear wall, improve structural load-carrying capacity and seismic capacity.

(5) When positive load is applied, the shear force is borne mainly by the oblique reinforced fixed at the right end of the bottom beam, reinforcement stirrup of the oblique reinforced fixed at the left end of the bottom beam and distribution reinforcement; When reverse load is applied, the shear force is borne mainly by the oblique reinforced fixed at the left end of the bottom beam , reinforcement stirrup of the oblique reinforced fixed at the right end of the bottom beam and distribution reinforcement.

\section{Conclusions}

( 1 ) In the shear wall structure, reasonable configuration of the oblique reinforced can slow down the strain variation of the distribution reinforcement, improve the horizontal ultimate bearing capacity of the structure.

( 2 ) Strain variation trend of the distribution bar with diagonal bracing shear wall is similar to that of the ordinary shear wall structure, which indicates that the stress characteristics of the distribution bar are not changed by the diagonal bracing.

( 3 ) The load - strain curve of the distribution bar is linear before the load reaches the yielding load; After yielding load, the residual strain of distribution bar with the oblique support structure is smaller and the seismic behavior is better.

( 4 ) Oblique support can bear part of the shear force, heighten the structural ductility performance, improve the structural deformation capacity, enhance structural seismic effect, but it can not replace distribution reinforcement of the shear wall completely.

\section{Acknowledgements}

This work was financially supported by the Jilin Science and Technology Foundation (20150203014SF, 2012200, 2015267).

The authors gratefully acknowledge the Natural Science Foundation of China (No.51378238).

\section{References}

[1] Jiaru Qian,Zao Jiang,Xiaodong Ji.Experimental study on seismic behavior of concrete filled steel tube shear wall with high axial compression ratio,J,Journal of architectural structure,(2011),31 
(1),40-48.

[2] Kuiming Li,Jie Li.Journal of reinforced concrete coupling beam of short leg shear wall structure test[J].Journal of Tongji University (NATURAL SCIENCE EDITION),(2009),37(5),593-595.

[3] Xinling Wang,Jianwei Fan,Hua Wang.Experimental study on seismic test of damaged RC frame strengthened with CFRP sheets,J,World Earthquake Engineering,(2009),25(3),121-123. 